\title{
Congenital tick-borne relapsing fever: report of a case with transplacental transmission in the Islamic Republic of Iran
}

\author{
M. Mahram ${ }^{1}$ and M.B. Ghavami ${ }^{2}$
}

\section{Introduction}

Tick-borne relapsing fever (TBRF) is an arthropod-borne infection found in the Middle East, Africa, Europe and North America. The disease is caused by several species of Borrelia and transmitted by various species of soft ticks [1,2]. Specific relationships usually exist between Borrelia species, the vector ticks and the distribution area [3]. Ornithodoros tholozani is distributed in the Middle East and is known as the main vector and sole reservoir for B. persica, which is often responsible for old-world TBRF. Ticks of this species live in close proximity with humans host and feed for short periods, through a painless bite, often at night [4].

TBRF is endemic in the north-west of the Islamic Republic of Iran where clinical and epidemiological studies have been conducted $[5,6]$. It is more prevalent in children under 5 years and pregnant women. In infected pregnant women, transplacental transfer of the microorganism is possible, which leads to neonatal infection. Although the mothers may have nonspecific febrile illnesses, the infected infants may present with severe disease. Most of the previ- ous studies concern children and adults, whereas no studies have been published on neonatal borreliosis in the Islamic Republic of Iran [6,7]. In this study, we report the clinical and laboratory results of a neonate infected with $B$. persica.

\section{Case report}

A full-term male 7-day-old neonate was admitted with malaise, weakness of neonatal reflexes and jaundice. At the time of admission there were no positive signs or symptoms, such as fever, hepatosplenomegaly or respiratory distress. The parents did not report any history of previous diseases in the mother during pregnancy or before. Based on the primary clinical findings, empirical antibiotic therapy with ampicillin and gentamicin was administered. Chest Xray and urinalysis were normal and blood and urine cultures were negative. Complete blood count was normal except for reduced platelet count of $46000 / \mathrm{mm}^{3}$ (repeat test in another sample was $\left.34000 / \mathrm{mm}^{3}\right)$. Total bilirubin level was elevated at $19 \mathrm{mg} / \mathrm{dL}$, with direct bilirubin of $0.3 \mathrm{mg} / \mathrm{dL}$ (Table 1 ).

${ }^{1}$ Department of Paediatrics, Vali-e-Asr Hospital, Zanjan University of Medical Sciences, Zanjan, Islamic Republic of Iran (Correspondence to M. Mahram: drmahram@yahoo.com).

${ }^{2}$ Department of Parasitology, Faculty of Medicine, Zanjan University of Medical Sciences, Zanjan, Islamic Republic of Iran.

Received: 14/10/06; accepted: 16/11/06

المجلة الصحية لشرق المتوسط، منظمة الصحة العالمية، المجلد الخنامس عشر، العدد ب، 9 +. 


\begin{tabular}{lc}
\hline \multicolumn{2}{l}{ Table 1 Laboratory results of a 7-day-old } \\
newborn infected with Borrelia persica in \\
Zanjan, north-west Islamic Republic of Iran \\
\hline Variable & Value \\
\hline Complete blood count and & \\
differentiation & \\
White blood cell count (/mm ${ }^{3}$ ) & 15800 \\
Polymorpholeukocytes (\%) & 55 \\
Lymphocytes (\%) & 40 \\
Monocytes (\%) & 4 \\
Eosinophils (\%) & 1 \\
Haemoglobin level (g/dL) & 17.2 \\
Haematocrit & 53 \\
Platelet count (/mm3) & \\
(repeat test) & $46000(34000)$ \\
Other tests & \\
Reticulocyte count (\%) & 0.6 \\
Erythrocyte sedimentation & \\
rate (mm/h) & 6 \\
C-reactive protein level (mg/L) & 15 \\
Total bilirubin level (mg/dL) & 19 \\
Direct bilirubin level (mg/dL) & 0.3 \\
Blood sugar level (mg/dL) & 267 \\
Blood urea nitrogen level & \\
(mg/100 mL) & 20.6 \\
Creatinine level (mg/dL) & 0.3 \\
Total calcium (mEq/L) & 9.3 \\
Sodium (mEq/L) & 134 \\
Direct Coombs test \\
$\begin{array}{l}\text { Glucose-6-phosphate } \\
\text { dehydrogenase level }\end{array}$ \\
Urine analysis \\
$\begin{array}{l}\text { Urine culture } \\
\text { Blood culture }\end{array}$ \\
\hline
\end{tabular}

During the first 2 days of admission, while the patient was receiving the antibiotics, his general condition deteriorated and we feared that a severe neonatal sepsis was starting. Despite the earlier historytaking, we discovered that the mother had had a febrile disease during the last days of her pregnancy and that a physician had administered doxycycline, which she had not taken.
In view of the regional epidemiology, and the antibiotics administered to the mother, we guessed that the mother's febrile disease could have been borreliosis. We therefore prepared a peripheral blood smear from the baby and found a large number of Borrelia isolates on the smear. Poikilocytosis, especially acanthocytosis in red blood cells, was observed, rather than borreliae (Figure 1).

After establishing the diagnosis of borreliosis in the patient, intravenous erythromycin was added to the previous treatment ( 40 $\mathrm{mg} / \mathrm{kg} / 24$ hour, every 6 hours). Following 24 hours of treatment with erythromycin, the general condition of the baby improved rapidly. Treatment was continued for 10 days, and finally the patient was discharged in a very good clinical condition, without jaundice and with a platelet count of $462000 / \mathrm{mm}^{3}$.

\section{Discussion}

In view of the age of the newborn at the time of admission and the presence of febrile disease in the mother during the last days of pregnancy, we conclude that borreliosis was transmitted through the transplacental route. However, some articles have reported vertically transmission as a possible route of acquiring the infection in newborns [8,9].

Although several reports of TBRF have been published, relatively few reports of neonatal TBRF could be found, due either to underdiagnosis or to its actually being a rare disease. In a report from Ardabil province in north-west of Islamic Republic of Iran, none of 391 known cases of TBRF were in the neonatal period [6]. In another study in 11 western states of the United States of America and in British Colombia, of 450 known cases of TBRF, including 6 pregnant women, 2 patients were newborns 


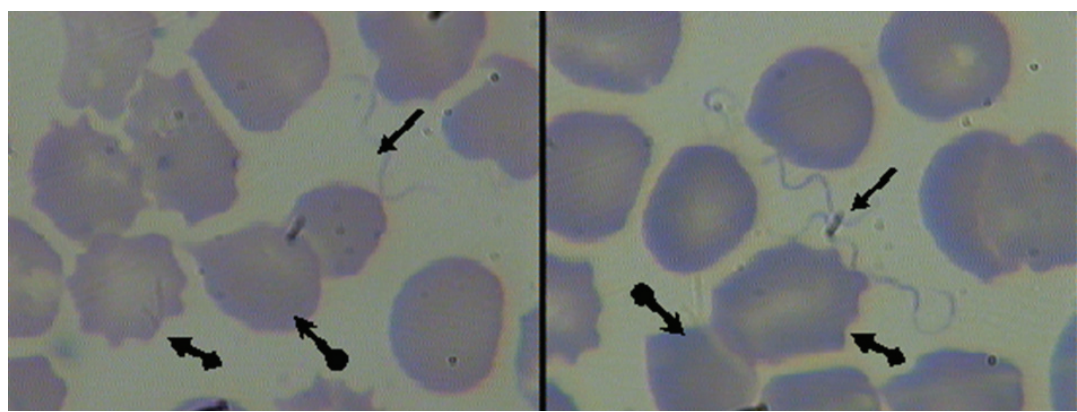

Figure 1 Spirochete; acanthocytosis; and poikilocytosis of erythrocytes in a thin smear of peripheral blood with Giemsa stain

[10]. Both reported cases had the signs and symptoms of fulminant sepsis and neonatal jaundice, similar to our case, although hepatosplenomegaly, which was present in both cases, was absent in our case. Haemorrhage was reported in one of the newborns, and severe acidosis in the other, and both died 16 and 24 hours after admission respectively [10].

In another report from an endemic region for tick-borne TBRF in Tanzania, East Africa, 5 cases of neonatal borreliosis were reported. It was mentioned that previously only 20 newborns with TBRF had been diagnosed in that endemic area. Among those cases, 4 had neonatal jaundice, 2 showed signs of septicaemia and 3 of them eventually died. According to that report, in 2 newborns with severe spirochetaemia, the one treated with low-dose penicillin died and the other treated with erythromycin survived [10]. Our experience with eryth- romycin treatment is similar to theirs, and this antibiotic seems to be an effective drug in treatment in newborns with borreliosis, even in severely ill cases.

As mentioned above, poikilocytosis and acanthocytosis were the main feature of the peripheral blood smear, rather than spirochetaemia. We cannot know if there was any link between the infection and these observations, and as there are no similar reports, we recommend further study on this issue.

We conclude that in endemic regions for TBRF, neonatal borreliosis should be considered for every newborn admitted with the impression of neonatal sepsis, and a history of febrile disease in the mother during her pregnancy, especially in the last days of pregnancy, should be taken. Obtaining peripheral blood smears at least 3 times from the baby is necessary to diagnose the main disease.

\section{References}

1. Azimi P. Relapsing fever (Borrelia). In: Behrman RE, Kliegman RM, Jenson $\mathrm{HB}$, eds. Nelson textbook of pediatrics, 17th ed. Philadelphia, WB Saunders, 2004:985.
2. Christenson SC. Relapsing fever. In: Jenson HB, Baltimore RB, eds. Pediatric infectious diseases, 2nd ed. Philadelphia, WB Saunders, 2002:387-8. 
3. Rebaudet S, Barola S. Epidemiology of relapsing fever borreliosis in Europe. FEMS immunology and medical microbiology, 2006, 48:11-5.

4. Barbour AG, Hayes S. Biology of Borrelia species. Microbiological reviews, 1986, 50(4):381-400.

5. Ghavami MB, Asmar M, Piazak N. [Epidemiology of tick borne relapsing fever in Zanjan city]. Journal of the Zanjan University of Medical Sciences, 2002, 9(37):22-7 [in Farsi].

6. Arshi $\mathrm{S}$ et al. Relapsing fever in Ardabil, a north-western province of Iran. Archives of Iranian medicine, 2002, 5(3):141-5.

7. Janbakhsh B, Ardelan A. The nature of sporadic cases of relapsing fever in $\mathrm{Ka}$ - zeroon area, southern Iran. Bulletin de la Société de pathologie exotique et de ses filiales, 1977, 70:587-9

8. Brasseur D. Tick-borne relapsing fever in a premature infant. Annals of tropical paediatrics, 1985, 5:161-2.

9. Yagupsky P, Moses S. Neonatal Borrelia species infection (relapsing fever). American journal of diseases of children, 1985 , 139(1):74-6.

10. Melkert PW, Stel HV. Neonatal Borrelia infection (relapsing fever): reports of 5 cases and review of the literature. East African medical journal, 1991, 68(12):9991005.

\section{Vector biology and control}

The Vector Biology and Control unit in WHO/EMRO aims to support Member States in reducing the burden of the major vector-borne diseases through the promotion and strengthening of cost-effective and sustainable vector control interventions in the context of integrated vector management in line with the recommendations contained in Resolution EM/RC.52/R.6. The programme also maintains a special focus on promoting multisectoral cooperation for implementation and resource mobilization, and advocacy and strengthening of national capacity in entomology and vector control.

Further information about the work of WHO/EMRO in vector control can be found at: http://www.emro.who.int/vbc/ 